\title{
STUDIES ON CAPTURE PROCESS AND FISH BEHAVIOUR TOWARDS MILLENNIUM GILL NET IN BONDET WATERS, CIREBON
}

\author{
Carolina Catur Rakhmadevi ${ }^{1)}$, Ari Purbayanto ${ }^{2)}$, and Muhammad Fedi Alfiadi Sondita ${ }^{2)}$ \\ 1) Graduate School Student of Marine Technology Study Program, Bogor Agricultural University, Bogor \\ 2) The Chairman and Member Supervisors \\ Received April 24-2008; Received in revised form May 15-2008; Accepted May 26-2008
}

\begin{abstract}
The millennium gill net was recently adopted by Cirebon fishermen. Its use has been spread to other areas. Research on this type of gear has been rare. The objectives of this research were to investigate the effects of transparency on the fish behaviour towards net panel of millennium gill net and to obtain the information on catch composition and the capture process of millennium gill net. This research consisted of laboratory experiment and experimel ial fishing. The laboratory experiment was conducted in August 2005 to March 2006 at Fish Behaviour Laboratory, Tokyo University of Marine Science and Technology, to analyze the effect of net colour transparency. The experimental fishing was carried out in October to November 2006 in waters off Cirebon to reveal the catch composition and the capture process of millennium gill net. The results of the experiments showed that net transparency affected on the Japanese Jack mackerel behaviour towards contrast colour net panel, the reduced transparency caused by the length of usage was not significant. Catch of millennium gill net in the field dominated by threadfins (71.29\%) and the other catch were bycatch, and capture process of millennium gill net dominated by gilled and wedged
\end{abstract}

KEYWORDS: fish behaviour, millennium gill net, capture process, catch composition, contrast colour

\section{INTRODUCTION}

The development of fishing technology in Indonesia can not be separated from the progress of fishing science, including the knowledge of gear and catch. The knowledge of catch includes the study of target fish, using fish hehaviour approach. The knowledge on fishing gear and its catch are important factors on understanding the capture process, in order to improve effectiveness and efficiency.

One of the common fishing gears used in Indonesia including in the north coast of Java, is gill net. Various tvpes of gill net are popular among fishermen in the north coast of Java Sea, especially in Cirebon.

The development of gill net fishing technology in the north coast of Java has been enriched by adoption of new technology. Around the year of 2000, millennium gill net from South Korea was intrciduced in Gebang Mekar Village, Cirebon. This gear was introduced by the local fishermen who had visited South Korean fishing industry. Soon, the use of this gill net expanded in another area in Mertasinga Village, Cirebon through a short training held by the local Fisheries and Marine Affairs Agency. Nowadays, the existence of this net is spreading to other areas in the north coast Java sea (Indramayu) as well as Semarang (Central Java) and Pontianak (West Borneo).

The underwater transparency of millennium gill net is trusted by fishermen affecting on the number of fish to be caught. Net with less transparency should be less contrast to its environment, and then it is less visible to the fish which eventually more easily caught by the net if the fish has to pass the net. In contrary, if the fish is attracted by the net, the net should be noticeable by the fish. The new millennium gill net itself is transparent (on each monofile nylon thread) but its transparency becomes less after used.

The existence of millennium gill net has replaced the use of nylon gill net that was used before by fishermen to catch the same target of fish in the same average size. The nylon gill net is made of nylon multifilament, while the millennium gill net is made of multi monofilament. According to Hovgard \& Lassen (2000), ny'. n multi monofilament is made of a number of monofile nylon thread or monofilaments in parallel. Multi rnonofilament nets are generally considered the most efficient as the use of thin parallel threads make the net softer than the monofilament or multifilament (Hovgard \& Lassen, 2000). It makes the multi monofilament nets more flexible underwater.

Even though this type of gill net has been accepted and well implemented in Cirebon, the information on its use for catching pelagic tish, the capture process of this gill net, and the effect of its net transparency related is very limited. Therefore it is necessary for understanding the catch performance and improving the millennium gill net to catch more effective.

The objectives of this research are as follows: 
1 To investigate the effects of transparency on the fish behaviour towards net panel of millennium gill net.

2 To obtain the information on catch composition and capture process of millennium gill net.

\section{MATERIALS AND METHODS}

\section{Fish Behaviour Towards Contrast Colour of Net}

The fish behaviour study was conducted in Fish Behaviour Laboratory, Tokyo University of Marine Science and Technology in August until September 2005 (fish behaviour towards contrast colour net panel) and December 2005 until March 2006 (fish behaviour study using specific white net panel). Fish behaviour towards contrast colour net panel experiment used three netting panels as treatment of transparency (i.e. old, new, and black painted net panel) and panel without a net as control. The reason of using these netting panels was that most fishermen in Cirebon use old net to catch fish instead of new net due to minimize cost. In this experiment, old net panel is the millennium gill net which has been used for 1.5 years. The old net was considered less transparent than the new gill net, whether it would affect the behaviour of fish on passing through the net panel is one of the objectives that will be analyzed. Black painted net panel is representation of nylon gill net, which mostly has dark in colour (dark blue). Furthermore, the fish behaviour towards contrast colour net panel experiment was continued by experiment using specific white net panel as treatment, the old white net and new white net with an addition of the white dyed net panel. The reason of using the white dyed net was to add more choices on white transparency of net panel. The panel without a net also used as a control.

For fish behaviour towards contrast colour net panel experiment, statistical test for significant difference (á $=0.05$ ) between the proportion of individual passing the net was carried using two way Anova. Software SPSS $v 12$ was used as the analysis tool for statistical test. For the behaviour experiment using specific white net panel, statistical test for significant difference $(a ́=0.05)$ between the proportion of individual passed the net was carried out using one way Anova.

\section{Capture Process}

Experimental fishing operations were conducted in October to November 2006 at Bondet waters, Cirebon Regency using a commercial fishing unit. The data recorded in each operation was capture process, time duration for each operation stage and catch number in millennium gill net according to the captured conditions (snagged, gilled, wedged, and entangled) with reference to the species and size. Ten replicates were conducted and each replicate was presented by one fishing operation (setting hauling). The total length and body girth of fish caught were measured to the nearest centimetre. The catch data (number of individual) presented descriptive analysis using graphics and mean values. The captured condition was analyzed in the form of proportion of each capture method category (i.e. gilled, wedged, snagged, and entangled).

\section{RESULTS AND DISCUSSIONS}

\section{Fish Behaviour Towards Contrast Colour of Net}

From the result of experiment, the largest frequency of fish entering the new white net panel was on the conditioned behaviour (106 times), while fish tended to enter the old white net panel on the voluntary behaviour (101 times). Otherwise the frequency of fish entering both net panels (old white and new white net) was higher than the frequency of fish entering black net panel. From the proportion of fish passing through net, the highest average was on the new white net with voluntary behaviour $(0.577)$. Proportion value analyzed by the frequency on fish passed through each net panel divided into frequency of fish passed through control. Frequency of fish entering black net was less than the new and old white net panel.

As shown in Figure 1, most fish (in voluntary and conditioned behaviour) avoiding the black net. From the result of two way Anova (á=0.05), the new white net in voluntary behaviour was significantly different in proportion of fish passing through the net panel.

According to the significant test between the three netting panels, it shows that the comparison between the new white net and black painted net was highly significant $(p<0.05)$.

Tweddle \& Bodington (1988) compared the effectiveness of black and white gill nets in Lake Malawi, Africa. They considered that white gill nets were more effective than the black net. For the net in Lake Malawi, it was not the invisibility of a gill net that makes it an efficient catcher of fish, but the nature of its visibility. It seems that most Lake Malawi fish were more likely to attempt to force a passage through a curtain of white netting rather than the black one and hence are at greater risk of getting tangle therein. This probably also happened to the fish in this experiment. Since fishes were able to recognize both 
existence of gill net (white and black). White netting was visible to the schooling of fish of Jack mackerels, but black net was more visible.

The behaviour of fish recorded on video tape showed that Japanese Jack mackerels tended to swim in circular movement around and near the net panel with their schooling; after succeeding in passing the net and entering the other side of experimental tank (area A), they tend to return to the previous side (area B), and join their schooling; Japanese Jack mackerel did the reaction behaviour when they recognized the existence net panel on their swimming movement, stop first, and tried to pass the net panel; and Japanese Jack mackerels avoided the black net.
Voluntary behaviour

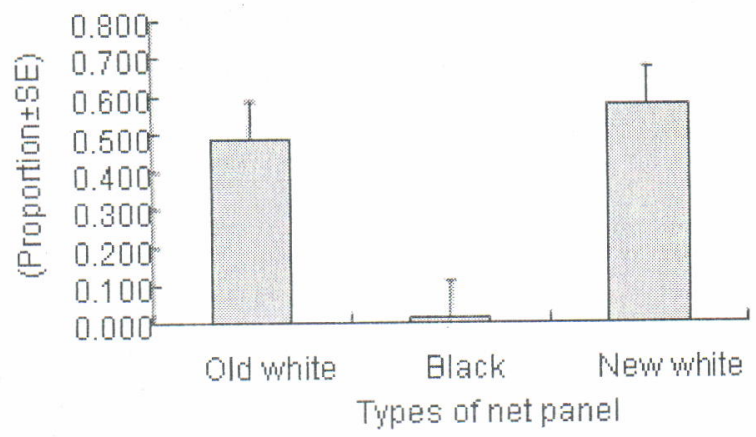

Conditioned behaviour

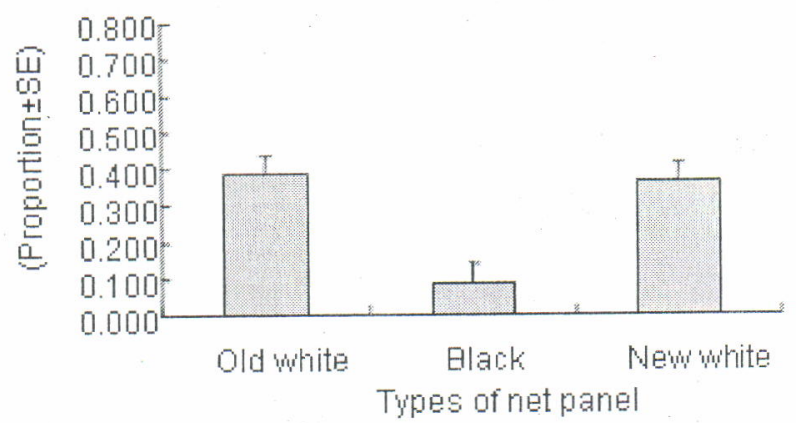

Figure 1. Comparison of fish passing through the net panel.

\section{Behaviour Experiment Using Specific White Net Panel}

As the result of the frame on frame analysis on mini DV, fish could recognize the existence of the net panel since the distance is around $20 \mathrm{~cm}$ in front of the net. When the schooling recognized the existence of the net panel, in natural condition, they would avoid to pass and just swimming in circular. The Jack mackerels were not very active in voluntary unless they are given some stimulus, for example to herd their swimming movement, the treatment that was given as conditioned behaviour on this experiment.
The proportion of fish passing through different transparency of net panel is shown in Figure 2. The proportion value derived from the frequency of fish passing through the net panel divided with the frequency of fish passing through the control panel (panel without a net). As we could see from the figure, old white net has the highest proportion of fish passing through net panel. Wardle et al. (1991) stated that the net colour or transparency appearance underwater was affected by many factors, at low intensities gill nets made by fine twines chosen to be relatively invisible to the fish. If the luminance of an object matches the luminance of the background then the object will see as invisible.

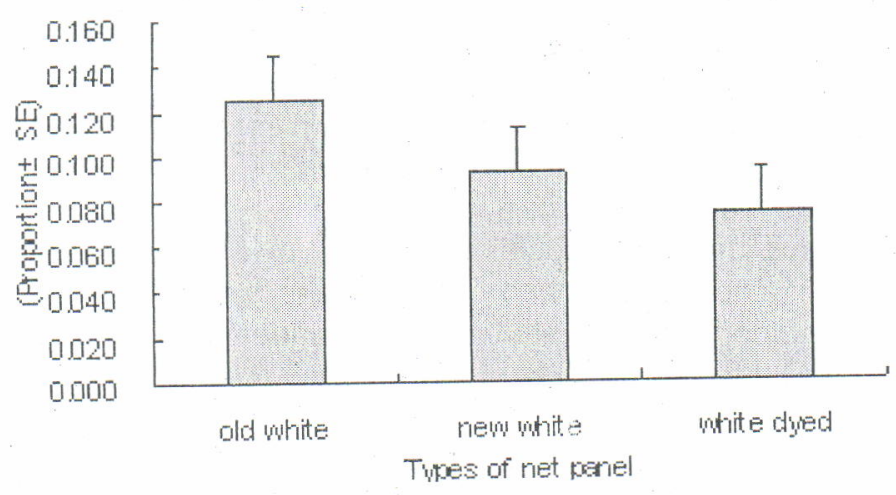

Figure 2. Comparison of fish passing through the net panel. 


\section{Net Passing Reaction of Fish}

As the result of observation on the conditioned behaviour, the behavioural reactions of fish when passing the net panel were classified into two types of behaviours, which passing through net with non contact or contact. Contact behaviour is when the fish passed through any contact of their body, while non contact is the opposites way. Proportion value derived from the frequency of fish passed through net panel of each of behaviour divided into total frequency of fish passed. Most fishes always tried to keep clear on net panel then try to pass through the net panel.

From the result of one way Anova on old white, new white and white dyed net panel showed that most fishes could pass through the net without any contact (Table 1). It means that non contact behaviour is significant behaviour reaction in all of net panel used on the experiment as shown in Figure 3.

Table 1.

Signification test of comparison proportion among three types of net panel

\begin{tabular}{lccc}
\multicolumn{1}{c}{ Net colour } & Old white & Black painted & New white \\
\hline Old white & & 0.072 & 0.967 \\
Black painted & & $0.049^{*}$ \\
New white & & \\
\hline
\end{tabular}
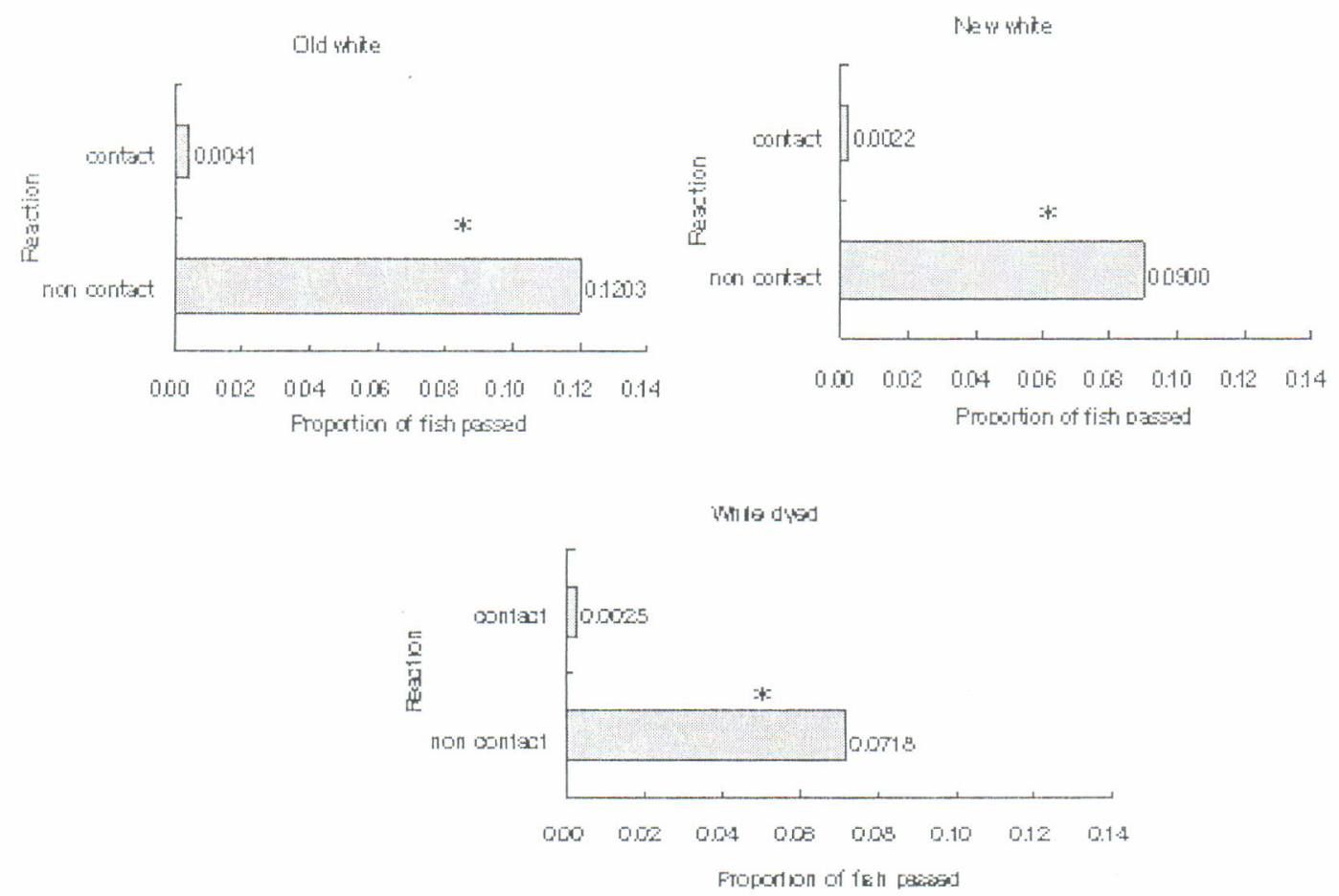

Figure 3. Contact and non contact reaction of fish passed through the net panel.

Wardle et al. (1991) stated that coloured line in shallow water can be more visible to some species of fish, particularly pelagic types with good colour vision. Near the sea bed, it may be more important to match the line to the sea bed. Because water colour can vary, colour in material adds a complication that could be avoided by careful selection of a neutral grey with density that results in a good match with the water background when vertical, as well as attenuating the glint when horizontal.

As the result of the experiment, most fishes tried to keep clear of the net panel. The number of fish passing the net panel also considering fluctuated.
Herding panel helped to create stimulation to fish to approach and penetrate meshes more readily. This was very important to understand their passing behaviour.

With one way Anova, the effect of white transparency on the number of fish passing through the net panel was not significantly difference. Even though, the proportion figure showed that fish avoiding to enter the more invisible net transparency, in this case the white dyed net, but still the other mesh panels are considered to have capability of facilitating fish to pass. 


\section{Capture Process Experiment}

The catch number of millennium gill net dominated by threadfins (Polynemus spp.) for $71.2871 \%$ of catch While bycatch consisted of striped catfish eel (Plotosus lineatus), spotted catfish (Arius maculatus), great barracuda (Sphyraena barracuda), triple tail (Labotes surinamensis), barramundi (Lates calcarifer), blue spotted snapper (Lutjanus rivulatus), silver pomfret (Pampus argentus), stingray (Dasyatis spp.), garfish (Hemirhampus spp.), and shark (Charcarinus spp.).

From the Figure 4, millennium gill net, mostly caught threadfins by gilled. The class range divided into 6 classes, the largest frequency is on 48 until $54.9 \mathrm{~cm}$ with 24 fish.

For the bycatch, the captured condition of fish depends on the species. Two largest bycatch, stripped catfish eel and spotted catfish caught mostly by gilled and wedged. On the other hand, spotted catfish mostly caught by gilled. For the rest of bycatch (i.e. great barracuda, triple tail, barramundi, blue spotted snapper, silver pomfret, stingray, garfish, and shark), the captured conditions come on a variation. The variation of captured condition depends on the species, but most fishes caught by gilled, and wedged. Shark was the only species caught by entangled.

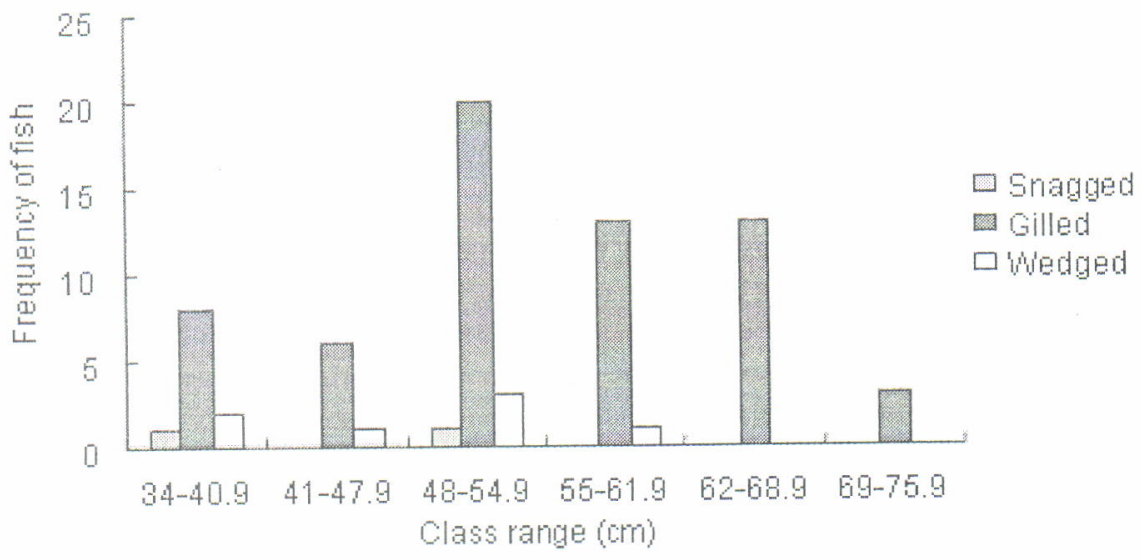

Figure 4. Captured conditions of threadfins on class range $(\mathrm{cm})$.

Captured conditions depend greatly on the length size and struggling effort. The small fishes, which body girth, were slightly better than the mesh perimeter could penetrate the mesh by their head and become finally snagged or gilled. Meanwhile, the medium or large fish whose body girth exceeds the mesh size could result into the complicated entanglement in the net by their violent struggling (Purbayanto et al., 1999). This was happening also by fish that caught in millennium gill net.

Most threadfins caught in the experiment did not have any injury on its body, but they have net like shape mark caused by fish being gilled. Some fishes have minor scale loss on the upper parts of the fish head and scar injuries and minor scale loss around the circumference of the maximum body girth. This was the same as the first and second pattern of fish caught by sweeping trammel net mentioned by Purbayanto (1999), which were minor scale loss on the upper parts of the fish head in front of dorsal fin and scar injuries and minor scale loss around the circumference of the maximum body girth.

\section{CONCLUSIONS AND RECOMMENDATIONS}

\section{Conclusions}

1. Net transparency affected on the Japanese Jack mackerel behaviour towards contrast colour net panel.

2. The reduced transparency caused by the length of usage was not significant.

3. Catch of millennium gill net in the field dominated by threadfins $(71.29 \%)$ and the other catch were bycatch.

4. Capture process of millennium gill net dominated by gilled and wedged.

\section{Recommendations}

1. Since the length of usage was not significantly affected on fish behaviour, the catching 
effectiveness maybe similar among millennium gill net net panel. The fishermen could continue the using of the old white panel until physically damaged.

2. It is recommended to conduct further experiment for investigate other factors that will affect the millennium gill net catch performance. Because this research did not carry out the same target species in Indonesia, and also did not conduct experiment regarding comparison of webbing material, multi monofilament.

\section{ACKNOWLEDGEMENTS}

This paper was part of Inhouse program titled riset dinamika spasial dan sumber daya perairan di Laut Jawa, Selat Makassar, dan Laut Flores, F.Y. 2005.

\section{REFERENCES}

Hovgard, H. \& Lassen H. 2000. Manual estimation of selectivity for gill net and longline gears in abundance surveys. http://www.fao.org/docrep/

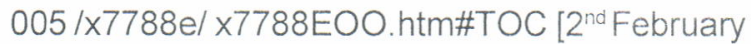
2007].

Purbayanto, A. 1999. Behavioral studies for improving survival of fish in mesh selectivity of sweeping trammel net. Thesis of Doctoral Course. Tokyo. Tokyo University of Fisheries. p. 105-133.

Purbayanto, A., S. Akiyama, T. Arimoto, \& M. F. A. Sondita 1999. Capture process of sweeping trammel net with special reference on operation method and catch pattern. Proceedings of The 3rd JSPS International Seminar on Fisheries Science in Tropical Area. Tokyo: TUF International JSPS Project Volume 8. p. 98-103.

Tweddle, D. \& P. Bodington. 1988. A comparison of the effectiveness of black and white gill nets in Lake Malawi, Africa. Journal Fisheries Resources. 6. 257-269.

Wardle, C. S., G. Cui, W. R. Mojsiewicz, \& C. W. Glass. 1991. The effect of colour appearance of monofilament nylon underwater. Journal Fisheries Resources. 10. 243-253. 